\title{
Gratitude, Psychopathology and Subjective Well-Being: Results from a 7.5-Month Prospective General Population Study
}

\author{
Lilian Jans-Beken ${ }^{1}$ (D) Johan Lataster ${ }^{1,2}$ (D) Denise Peels ${ }^{1} \cdot$ \\ Lilian Lechner $^{1}$ (D) Nele Jacobs ${ }^{1,2}$
}

Published online: 30 May 2017

(c) The Author(s) 2017. This article is an open access publication

\begin{abstract}
Gratitude is considered an important source of human strength in achieving and maintaining good mental health. Although complete mental health encompasses the absence of psychopathology and the presence of subjective well-being, no studies to date have examined relations between gratitude and both mental health dimensions together. Moreover, most studies focused on specific samples with a restricted demographic range. Our study, therefore, examined (a) demographic variability in the grateful trait, and (b) prospective associations between gratitude and both dimensions of mental health: psychopathology and subjective well-being. Using a four wave prospective survey design in a large $(N=706)$ sample of Dutch adults $(M$ age $=44, S D$ age $=14$, Range $=18-80$ ), we measured gratitude with the SGRAT, symptoms of psychopathology with the SCL-90, and subjective well-being with the PANAS and SWLS. Gratitude was significantly associated with age, gender, education level, and employment status. Multilevel time-lagged regression analyses showed that the grateful trait did not predict symptoms of psychopathology, but was a significant albeit weak predictor of subjective well-being, when adjusting for the effects of demographic factors, and prior levels of subjective well-being and psychopathology. Our findings indicate that the grateful trait is associated with demographic factors, and shows complex connections with the presence of well-being and absence of psychopathology. These dynamics should be taken into consideration when studying the role of gratitude in mental health, and developing, applying, and evaluating gratitude interventions with the aim of enhancing subjective well-being and/or reducing psychopathology.
\end{abstract}

Lilian Jans-Beken

info@lilianjansbeken.nl

1 Faculty of Psychology and Educational Sciences, Open University, P.O. Box 2960, 6401 DL Heerlen, The Netherlands

2 Department of Psychiatry and Psychology, School for Mental Health and Neuroscience, Maastricht University Medical Centre, Universiteitssingel 40, 6229 ER Maastricht, The Netherlands 
Keywords Grateful disposition · Psychological distress · Mental health ·

Life satisfaction · Dual continua model

\section{Introduction}

Gratitude as a disposition, also called the grateful trait, refers to a wider life orientation based on a sense of abundance, the appreciation of little things in life, and the appreciation of what others have done for us (Thomas and Watkins 2003). The grateful trait has been suggested to be an important source of human strength in achieving and maintaining good mental health (Emmons and Crumpler 2000; Snyder and Lopez 2009). Complete mental health, following Keyes' (2005) empirically grounded dual continuum model, consists of two related, yet distinct dimensions: psychopathology (or mental illness) and subjective well-being (or positive mental health; see also: Westerhof and Keyes 2010). Evidence suggests that the absence of psychopathology does not necessarily imply the presence of subjective well-being, and vice versa (Keyes 2005, 2007), and the study of mental health and determinants thereof should, thus, include the combined assessment of both dimensions (Keyes 2007).

Hence, a complete view of gratitude's contribution to mental health would require an examination of its effects on both psychopathology and subjective well-being. However, although a number of studies, both cross-sectional and longitudinal, have linked the grateful trait negatively to measures of psychopathology (Kleiman et al. 2013; Krause 2009; Lies et al. 2014; Petrocchi and Couyoumdjian 2016; Wood et al. 2008a), and other studies have reported positive associations between gratitude and measures of well-being (Chaves et al. 2015; Gillham et al. 2011; Kong et al. 2015; Szcześniak and Soares 2011; Thrash et al. 2010; Tsai et al. 2016; Watkins et al. 2003; Zhou and Wu 2015), no studies to date have examined relations between the grateful trait and both dimensions of mental health together. Our understanding of the grateful trait's contribution to mental health remains, therefore, incomplete, and calls for additional prospective examination of how gratitude impacts on the combinedly assessed dimensions of psychopathology and subjective well-being.

In addition, the majority of studies on the relationship between gratitude and mental health were carried out among adolescent (mainly student) convenience samples (Gillham et al. 2011; Kleiman et al. 2013; Kong et al. 2015; Petrocchi and Couyoumdjian 2016; Watkins et al. 2003; Wood et al. 2008a), among elderly individuals (Krause 2009), or among individuals within a particular psychological context, such as earthquake survivors (Lies et al. 2014; Zhou and Wu 2015), military veterans (Tsai et al. 2016), breast cancer survivors (Hulett et al. 2015), or children with a life threatening illness (Chaves et al. 2015). It remains uncertain to what extent the results produced by these studies reflect general patterns at the population level. Furthermore, most study samples-in particular the adolescent convenience samples - suffer from a restricted demographic range, and the gratitude literature in general, as pointed out by Watkins (2013), lacks adequate examination of demographic variation in the grateful trait. Apart from the consistent observation that women tend to be more grateful than men (Kaczmarek et al. 2015; Kashdan et al. 2009; Krause 2006; Sommers and Kosmitzki 1988), no strong or consistent demographic predictors of gratitude have emerged from the literature (see Watkins 2013 for review). However, given the dearth of large-scale systematic studies on the demographics of 
gratitude, no definite conclusions can be drawn as to whether the grateful trait is indeed distributed uniformly across demographic groups.

Our study aims to contribute to the empirical study of gratitude and its contributions to mental health, by addressing the abovementioned shortcomings in the present literature. Using a four-wave, 7.5 -months, prospective survey design in a large $(N=706)$ general population sample of Dutch-speaking adults, we examined (a) demographic variability in the grateful trait, and (b) the prospective associations between gratitude and both dimensions of mental health: psychopathology and subjective well-being. We hypothesized that higher levels of gratitude would be longitudinally associated with lower levels of psychopathology and higher levels of subjective well-being, and that these associations would not be reducible to demographic characteristics or correlations in psychopathology and subjective well-being across time.

\section{Materials and Methods}

\subsection{Sample}

The sample at baseline (T0) consisted of 706 Dutch speaking respondents $(M$ age $=44$, $S D$ age $=14$, Range 18-80), among which 220 men (31\%). Inclusion criteria were: (a) at least 18 years old, and (b) sufficient command of the Dutch language to understand instructions and give informed consent. No exclusion criteria were applied to obtain a demographically heterogeneous sample. Demographic characteristics of the total sample, and a comparison of completers (respondents who completed all four measurements) and dropouts (respondents who dropped out of the study at one of the follow-up measurements $\mathrm{T} 1, \mathrm{~T} 2$, or T3) are reported in Table 1. Response rates relative to baseline on T1, T2, and T3 assessments were, respectively, 62\% $(n=440), 45 \%(n=321)$, and $40 \%(n=280)$. Respondents participated voluntarily and were rewarded with a raffle for gift cards. The study was carried out in accordance with The Code of Ethics of the World Medical Association (Declaration of Helsinki) for medical research involving humans. Informed consent was obtained from all respondents at study entry.

\subsection{Study Design and Procedure}

Our study employed a longitudinal prospective design, consisting of a baseline online survey (T0) and three follow-up online surveys (T1, T2, and T3), covering a time period of 6,18 , and 30 weeks from baseline, respectively. Respondents were recruited through doorto-door flyers, social media, email, and face-to-face contact. Those who participated in the first measurement received an email with the request to fill out the second online survey that could be accessed by clicking on a link and logging in with a unique 15 character personal access code. This procedure was repeated for respondents who participated in the second and third measurement.

\subsection{Measures}

\subsubsection{Gratitude}

The grateful trait was measured with the Dutch Short Gratitude, Resentment, and Appreciation Test (SGRAT-nl; Jans-Beken et al. 2015; McCullough et al. 2002). The 
Table 1 Sample characteristics of total sample $(N=706)$, and dropout-completer comparison

\begin{tabular}{|c|c|c|c|c|}
\hline & Total sample & Dropouts & Completers & $\Delta$ Dropouts-completers \\
\hline$N$ & $706(100)$ & $426(60)$ & $280(40)$ & \\
\hline Age $M(S D)$ & $44(14)$ & $41(14)$ & $48(14)$ & $t(704)=-6.370^{* *}$ \\
\hline [range] & {$[18-80]$} & {$[18-76]$} & [18-80] & \\
\hline \multicolumn{5}{|l|}{ Gender $n(\%)$} \\
\hline Men & $220(31)$ & $140(33)$ & $80(29)$ & \multirow[t]{2}{*}{$\chi^{2}(1, N=706)=1.451$} \\
\hline Women & $486(69)$ & $286(67)$ & $200(71)$ & \\
\hline \multicolumn{5}{|c|}{ Relationship status $n(\%)$} \\
\hline Single & $201(29)$ & $120(28)$ & $81(29)$ & \multirow[t]{2}{*}{$\chi^{2}(1, N=706)=0.048$} \\
\hline In a relationship & $505(71)$ & $306(72)$ & $199(71)$ & \\
\hline \multicolumn{5}{|l|}{ Family status $n(\%)$} \\
\hline $\begin{array}{l}\text { Not living with } \\
\text { underage children }\end{array}$ & $464(66)$ & $264(62)$ & $200(71)$ & \multirow[t]{2}{*}{$\chi^{2}(1, N=706)=6.707 *$} \\
\hline $\begin{array}{l}\text { Living with } \\
\text { underage children }\end{array}$ & $242(34)$ & $162(38)$ & $80(29)$ & \\
\hline \multicolumn{5}{|l|}{ Education level $n(\%)$} \\
\hline Low education & $94(13)$ & $65(15)$ & $29(11)$ & \multirow[t]{3}{*}{$\chi^{2}(1, N=706)=5.110$} \\
\hline Medium education & $140(20)$ & $89(21)$ & $51(18)$ & \\
\hline High education & $472(67)$ & $272(64)$ & $200(71)$ & \\
\hline \multicolumn{5}{|c|}{ Employment status $n(\%)$} \\
\hline Full-time & $285(40)$ & $187(44)$ & $98(35)$ & \multirow[t]{3}{*}{$\chi^{2}(1, N=706)=5.834$} \\
\hline Part-time & $242(35)$ & $140(33)$ & $102(36)$ & \\
\hline Not employed & $179(25)$ & $99(23)$ & $80(29)$ & \\
\hline SGRAT-nl $M(S D)$ & $110.78(15.38)$ & $110.00(15.04)$ & $111.98(15.84)$ & $t(704)=-1.675$ \\
\hline SCL-90 $M(S D)$ & $38.24(37.22)$ & $37.25(35.15)$ & $39.61(39.92)$ & $t(704)=-0.807$ \\
\hline SWLS $M(S D)$ & $24.58(6.24)$ & $24.45(6.42)$ & $24.78(5.97)$ & $t(704)=-0.683$ \\
\hline PA-scale $M(S D)$ & $35.09(6.64)$ & $35.03(6.77)$ & $35.18(6.45)$ & $t(704)=-0.294$ \\
\hline NA-scale $M(S D)$ & $19.17(7.03)$ & $19.67(7.43)$ & $18.41(6.32)$ & $t(704)=2.331 *$ \\
\hline SWB $M(S D)$ & $40.50(15.51)$ & $39.80(15.77)$ & 41.56 (15.07) & $t(704)=-1.474$ \\
\hline
\end{tabular}

** $p<0.001 ; * p<0.05$. Dropouts are respondents who dropped out of the study at one of the follow-up measurements T1, T2, or T3. Completers are respondents who completed all four measurements

SGRAT-nl consists of 16 propositions, for example "Life has been good to me". Respondents indicated their response on a 9-point Likert scale, ranging from strongly disagree (1) to strongly agree (9). Five negatively formulated items were reverse coded, and item scores were summed to a total score, ranging from 16 to 144, with high scores indicating a higher level of a grateful trait. The SGRAT-nl is previously found to be a reliable measure (Jans-Beken et al. 2015), and McDonald's $\omega_{\text {total }}$ reliability coefficients for the samples in the current study (T0-T3) showed a satisfactory range of .88 to .92. The SGRAT-nl showed high test-retest reliability across the four measurements in the current study: $\operatorname{ICC}(3, \mathrm{k})=.93,95 \%$ CI $[.92, .94]$ (see Terwee et al. 2007 for interpretation conventions). 


\subsubsection{Psychopathology}

To assess symptoms of psychopathology, the Dutch version of the Symptom Check List-90 was used (SCL-90; Arrindell and Ettema 1981; Derogatis 1977). The SCL-90 is used as a screening instrument for a broad range of psychological problems and symptoms of psychopathology and consists of 90 symptoms (e.g. "Experiencing feelings of worthlessness", "Feeling an urge to check things that you do", and "Feeling afraid"), comprising 8 subscales and a total score providing an overall measure of psychopathology. Respondents were asked to rate the extent to which they experienced each symptom during the last week on a scale from 0 (not at all) to 4 (extremely). The current study used the total score, ranging from 0 to 360 , as a measure of psychopathology. The Dutch SCL-90 has been proven to be a reliable and valid measure of psychopathology (Arrindell and Ettema 1981). For the samples in the current study, McDonald's $\omega_{\text {total }}$ reliability coefficients for the SCL90 ranged from .98 to .99 , and test-retest reliability across the four measurements was high: $\operatorname{ICC}(3, \mathrm{k})=.91,95 \%$ CI $[.90, .92]$.

\subsubsection{Subjective Well-Being}

To assess subjective well-being we employed the approach previously described by Diener (1994): scores of life satisfaction were added to net affect scores (positive minus negative) to obtain a composite measure of subjective well-being. To measure life satisfaction the Dutch version of the Satisfaction With Life Scale (SWLS: Arrindell 1991; Diener et al. 1985) was used, and the Dutch Positive Affect and Negative Affect Schedule (PANAS: Peeters et al. 1996; Watson et al. 1988) was used to measure positive and negative affect. For the SLWS, respondents were asked to rate their response to five propositions, e.g. "I am satisfied with my life", on a 7-point Likert scale, ranging from strongly disagree (1) to strongly agree (7). All item scores were summed to a total score, ranging from 5 to 35, with high scores indicating a higher level of life satisfaction. The SWLS is found to be a reliable measure with reported Cronbach's $\alpha$ values in the range of 0.85 to 0.87 (Arrindell 1991; Van Beuningen 2012). In the samples of the current research, McDonald's $\omega_{\text {total }}$ reliability coefficients for the SWLS ranged from .87 to .89 , and test-retest reliability across the four measurements was high: $\operatorname{ICC}(3, \mathrm{k})=.92,95 \% \mathrm{CI}[.91, .93]$.

For the PANAS, respondents were asked to rate the extent to which they had experienced ten mood states, among which "interested" and "nervous", during the past week on a 5-point Likert scale, ranging from very slightly or not at all (1) to extremely (5). Scores on each affect dimension were summed to a total score, ranging from 10 to 50 for each dimension, with high scores indicating a higher level of positive or negative affect. Dutch translations of the negative affect scale and positive affect scale have shown internal consistencies of $\alpha=0.83$ and $\alpha=0.79$, respectively (Peeters et al. 1996). In the samples of the current research, McDonald's $\omega_{\text {total }}$ reliability coefficients for the PANAS showed a range of .89-.90 for the negative affect scale, and .86-.90 for the positive affect scale. Both scales showed moderate to high test-retest reliability across the four measurements in the current study (NA: $\operatorname{ICC}(3, \mathrm{k})=.80,95 \%$ CI $[.78, .83]$; PA: $\operatorname{ICC}(3, \mathrm{k})=.81,95 \%$ CI $[.78$, $.83])$. For the combined subjective well-being scale, McDonald's $\omega_{\text {total }}$ reliability coefficients showed a satisfactory range of .93-.94, and test-retest reliability across the four measurements was high: $\operatorname{ICC}(3, \mathrm{k})=.89,95 \%$ CI $[.87, .90]$. 


\subsection{Statistical Analyses}

Analyses were performed using STATA version 14.0 (StataCorp 2015), and R version 3.3.2 (R Core Team 2016) psych package (Revelle 2014) for calculating McDonald's $\omega$ and intraclass correlation coefficients. All findings were interpreted against a significance threshold of 5\%. For regression analyses, all continuous variables were standardized to facilitate the interpretation of effect coefficients (Hox 1995).

\subsubsection{Dropout-Completer Comparison}

To assess differences in demographic composition between dropouts and completers, Chi square and unpaired $t$ tests were performed, testing for differences in age, gender, relationship status, family status, education level, and employment status. Using unpaired $t$ tests, we additionally tested differences between dropouts and completers in baseline scores on the grateful trait, symptoms of psychopathology, life satisfaction, positive and negative affect, and the composite subjective well-being measure.

\subsubsection{Demographic Variability in the Grateful Trait}

Using the measures obtained at baseline, cross-sectional associations between demographic characteristics and the grateful trait were analyzed using multiple regression analysis.

\subsubsection{Prospective Associations Between Gratitude and Symptoms of Psychopathology}

Given the prospective study design and hierarchical structure of the data, i.e. multiple measurements (level 1) clustered within respondents (level 2), multilevel time-lagged regression analyses were conducted using the 'lag' ( $\mathrm{t}-1$ ) and 'xtreg' commands in STATA version 14.0 (StataCorp 2015). The level 1 intercept was allowed to vary randomly across respondents at level 2. The level 2 intercept and slope represent the average level 1 intercept and slope across the sample.

Four models of psychopathology were tested consecutively. Model 1 included only gratitude at the previous time point (t-1) as predictor. Model 2 included gratitude at the previous time point ( $\mathrm{t}-1)$, and age, gender, relationship status, family status, education level, and employment status as confounder variables. Model 3 included, in addition to the predictor variables specified in Model 2, also symptoms of psychopathology at the previous time point ( $\mathrm{t}-1)$ as predictor. Model 4, finally, included, in addition to the predictor variables specified in Model 3, also subjective well-being at the previous time point ( $\mathrm{t}-1)$ as predictor.

\subsubsection{Prospective Associations Between Gratitude and Subjective Well-Being}

Analogous to the model testing for the dependent variable psychopathology, four models of subjective well-being were tested consecutively. Model 1 included only gratitude at the previous time point $(\mathrm{t}-1)$ as predictor. Model 2 included gratitude at the previous time point (t-1), and age, gender, relationship status, family status, education level, and employment status as predictor variables. Model 3 included, in addition to the predictor variables specified in Model 2, also subjective well-being at the previous time point (t-1) as 
predictor. Model 4, finally, included, in addition to the predictor variables specified in Model 3, also symptoms of psychopathology at the previous time point (t-1) as predictor.

\section{Results}

\subsection{Demographic Characteristics and Dropout-Completer Comparison}

Table 1 presents a demographic description of the total sample, and a comparison between dropouts and completers. Dropouts were significantly younger than completers $(t(704)=-6.370, p<.001)$, lived more often in a household with underage children $\left(\chi^{2}\right.$ $(1, N=706)=6.707, p<.01)$, and reported higher levels of negative affect at baseline $(t(704)=2.331, p<.05)$.

\subsection{Demographic Variability in the Grateful Trait}

Gratitude as a trait at baseline showed significant associations with age, gender, education level, and employment status: older individuals, women, more highly educated individuals, and employed individuals reported higher scores of the grateful trait than younger individuals, men, individuals with lower education levels, and unemployed individuals, respectively. Having a relationship or having underage children was not associated with the grateful trait (see Table 2).

\subsection{Prospective Associations Between Gratitude and Symptoms of Psychopathology}

As illustrated in Table 3, the prospective model of the dependent variable psychopathology showed that the grateful trait was a significant negative longitudinal predictor of psychopathology symptoms (Model 1 estimate: $\beta=-.151, S E=.034, p<.001$ ), also when adjusted for the effects of demographic factors (Model 2 estimate: $\beta=-.129, S E=.034$, $p<.001)$. However, the prospective association between gratitude and psychopathology lost significance when adjusted for the effect of psychopathology at the previous time point (Model 3 estimate: $\beta=-.020, S E=.019, p=.299$ ). Model 3 outcomes showed that the presence of psychopathology symptoms at a given time point was the only significant

Table 2 Multiple regression analysis of associations between demographic variables and total score on the SGRAT-NL $(N=706)$

\begin{tabular}{lllll}
\hline Characteristic & $B$ & $S E$ & $\beta$ & $95 \%$ CI \\
\hline Age [18-80] & .283 & .046 & $.257 * * *$ & {$[.193, .373]$} \\
Gender (female vs. male) & 3.728 & 1.252 & $.111^{* *}$ & {$[1.271,6.185]$} \\
Relationship (in a relationship vs. single) & 1.170 & 1.307 & .034 & {$[-1.395,3.736]$} \\
Family status (parent vs. non-parent) & 1.990 & 1.242 & .061 & {$[-.448,4.428]$} \\
Education level (low vs. medium vs. high) & 3.856 & .819 & $.178^{* * *}$ & {$[2.248,5.463]$} \\
Employment status (not employed vs. part-time vs. full- & 1.705 & .790 & $.087 *$ & {$[.154,3.256]$} \\
$\quad$ time) & & & & \\
\hline
\end{tabular}

$* p<.05, * * p<.01, * * * p<.001$ 
Table 3 Multilevel models for the prospective effect of gratitude on psychopathology

\begin{tabular}{lllll}
\hline Parameters & Model $1 \beta(S E)$ & Model $2 \beta(S E)$ & Model $3 \beta(S E)$ & Model $4 \beta(S E)$ \\
\hline Fixed effects & & & & \\
$\quad$ Level 1 & & & & \\
$\quad$ Intercept & $.084(.070)$ & $.521(.178)^{* *}$ & $-.009(.093)$ & $.002(.093)$ \\
$\quad$ Gratitude (T-1) & $-.151(.034)^{* * *}$ & $-.129(.034)^{* * *}$ & $-.020(.019)$ & $-.035(.021)$ \\
$\quad$ Time & $-.034(.020)$ & $-.033(.020)$ & $-.007(.022)$ & $-.008(.022)$ \\
Age (standardized) & & $-.180(.054)^{* *}$ & $-.018(.022)$ & $-.022(.022)$ \\
Gender & & $.160(.100)$ & $.059(.041)$ & $.051(.041)$ \\
$\quad$ Relationship & $-.135(.099)$ & $.010(.040)$ & $.008(.040)$ \\
Family & $-.231(.099)^{*}$ & $-.068(.041)$ & $-.068(.041)$ \\
$\quad$ Education & & $-.149(.069)^{*}$ & $-.027(.028)$ & $-.028(.028)$ \\
$\quad$ Employment & $-.103(.063)$ & $-.008(.026)$ & $-.014(.026)$ \\
$\quad$ Psychopathology (T-1) & & & $.821(.018)^{* * *}$ & $.857(.027)^{* * *}$ \\
$\quad$ Subjective wellbeing (T-1) & & & & $.057(.030)$ \\
$\quad$ Random parameters & & & & \\
Level 2 & & & & \\
$\quad$ Intercept (id) & $.867(.035)$ & $.840(.034)$ & $.000(.000)$ & $.000(.000)$ \\
\hline$* p<.05, * * p<.01, * * * p<.001$ & & &
\end{tabular}

predictor of psychopathology one time point later (Model 3 estimate: $\beta=.821$, $S E=.018, p<.001)$, and remained so when further adding subjective well-being at the previous time point as a predictor to the prospective model of psychopathology (Model 4 estimate: $\beta=.857, S E=.027, p<.001)$.

\subsection{Prospective Associations Between Gratitude and Subjective Well-Being}

As can be seen in Table 4, the prospective model of the dependent variable subjective well-being showed that the grateful trait was a modest, but significant positive longitudinal predictor of subjective well-being (Model 1 estimate: $\beta=.287, S E=.033, p<.001$ ), and remained so when adjusted for the effects of demographic factors (Model 2 estimate: $\beta=.252, S E=.033, p<.001)$. Furthermore, gratitude remained a significant, albeit weak prospective predictor of subjective well-being when corrected for the effect of subjective well-being at the previous time point (Model 3 estimate: $\beta=.074, S E=.023$, $p<.001$ ), and when symptoms of psychopathology at the previous time point were additionally included in the model (Model 4 estimate: $\beta=.088, S E=.022, p<.001$ ). The variance in subjective well-being was, however, largely accounted for by the effects of subjective well-being and symptoms of psychopathology at the previous time point $(\beta=.545, S E=.033, p<.001$, and $\beta=-.208, S E=.029, p<.001$, respectively $)$.

\section{Discussion}

This longitudinal study in a large, demographically diverse, Dutch-speaking general population sample aimed to shed more light on the demography of gratitude, and the relationship between the grateful trait and the multidimensional construct of complete 
Table 4 Multilevel models for the prospective effect of gratitude on subjective well-being

\begin{tabular}{lllll}
\hline Parameters & Model $1 \beta(S E)$ & Model $2 \beta(S E)$ & Model $3 \beta(S E)$ & Model $4 \beta(S E)$ \\
\hline Fixed effects & & & & \\
$\quad$ Level 1 & & & & \\
$\quad$ Intercept & $-.103(.073)$ & $-.767(.161)^{* * *}$ & $-.263(.104)^{*}$ & $-.256(.101)^{*}$ \\
$\quad$ Gratitude (T-1) & $.287(.033)^{* * *}$ & $.252(.033)^{* * *}$ & $.074(.023)^{* *}$ & $.088(.022)^{* * *}$ \\
$\quad$ Time & $.037(.023)$ & $.035(.022)$ & $.033(.024)$ & $.028(.024)$ \\
Age (standardized) & & $.240(.047)^{* * *}$ & $.061(.025)^{*}$ & $.059(.024)^{*}$ \\
$\quad$ Gender & $.034(.088)$ & $-.032(.045)$ & $.010(.044)$ \\
$\quad$ Relationship & $.178(.086)^{*}$ & $.063(.044)$ & $.056(.043)$ \\
$\quad$ Family & $.210(.086)^{*}$ & $.108(.046)^{*}$ & $.086(.045)$ \\
$\quad$ Education & $.120(.060)^{*}$ & $.026(.031)$ & $.022(.031)$ \\
$\quad$ Employment & $.199(.055)^{* * *}$ & $.040(.029)$ & $.048(.028)$ \\
$\quad$ Subjective wellbeing (T-1) & & & $.715(.023)^{* * *}$ & $.545(.033)^{* * *}$ \\
$\quad$ Psychopathology (T-1) & & & & $-.208(.029)^{* * *}$ \\
Random parameters & & & & \\
Level 2 & $.697(.033)$ & $.000(.000)$ & $.000(.000)$ \\
$\quad$ Intercept (id) & & & &
\end{tabular}

mental health, incorporating both psychopathology and subjective well-being (Keyes 2005). First, our findings showed that gratitude as a trait is significantly associated with age, gender, education level, and employment. Secondly, higher levels of gratitude at one moment were shown to be weakly associated with lower levels of psychopathology, and moderately with higher levels of subjective well-being at a subsequent moment, irrespective of the effect of demographic factors. Thirdly, although the negative prospective effect of gratitude on psychopathology symptoms was reducible to correlations in psychopathology across time, the positive prospective effect of gratitude on subjective wellbeing, albeit weak, remained significant even when taking into account variance in subjective well-being attributable to prior levels of both well-being and psychopathology. Our findings indicate that the grateful trait is associated with demographic factors, and shows complex connections with the presence of well-being and absence of psychopathology, further elucidating the role of gratitude in complete mental health.

\subsection{Demographic Variation in the Grateful Trait}

Although levels of the grateful trait did not vary as a function of relationship or family status, gratitude as a trait at baseline was significantly associated with age, gender, education level, and employment status. These results do not support previous suggestions that the grateful trait is distributed uniformly across demographic groups (see Watkins 2013 for review).

As individuals age, they appear to report higher levels of gratitude (Wood et al. 2008b), a process that can be understood in the light of socio-emotional selectivity theory, stating that the awareness of mortality shifts attention to current happiness (Carstensen et al. 2003), in addition to being more prone to positive memories than younger individuals (Reed et al. 2014). Another explanation for the observed positive association between age 
and gratitude could be the previously described stability-despite-loss paradox; older individuals are more frequently confronted with disabled peers and deceased loved ones. As a consequence, they accept their strengths and weaknesses, and learn to appreciate life as it is (Kunzmann et al. 2000).

The current study showed women to be more grateful than men, a finding in line with several previous studies (Kashdan et al. 2009; Krause 2006). Drawing on the social role theory (Eagly 2013), one could suggest that women are more prone to social interaction and cooperation, established in the experience and expression of gratitude. Future research should, however, shed further light on the mechanisms underlying an increased sense of gratitude in women versus men.

A higher education level seems to be associated with higher levels of the grateful trait. This finding is interesting because previous research has shown that the well-established positive association between education level and healthy behavior (Singh-Manoux et al. 2004) is mediated by personality traits (Edmonds 2011). Given that gratitude also seems dispositional, and shows associations with both education level and mental health in our study data, its possible mediating role in the interrelationship of education level and health behaviors deserves further examination.

Employed individuals report higher levels of gratitude, in line with previous reports of unemployment being related to reduced physical and mental health (Wilson and Walker 1993) and subjective well-being (Clark and Oswald 1994). However, the effect of employment status on gratitude is rather small, fitting the idea that being employed in itself is not necessarily or solely predictive of gratitude, but the appreciation of work activities or lack thereof may represent a far more important predictor of gratitude (Šverko and Vidović 1995; Adler and Fagley 2005).

We found no associations between the grateful trait and relationship or family status. Higher levels of the grateful trait among couples have been previously associated with higher levels of relationship maintenance and partner responsiveness (Feeney and Collins 2014; Kubacka et al. 2011), behaviours that have been suggested to lie at the base of thriving relationships, and higher levels of subjective well-being in both partners (Feeney and Collins 2014). These studies only included couples, however, and further research is needed to systematically investigate the dynamics of gratitude in the context of interhuman relationships.

Being a parent is shown to evoke joy, positive affect, happiness, and meaning in life (Nelson et al. 2013). On the contrary, non-parents report higher quality of life than parents (Hansen 2012). The current study did not show gratitude to differ between parents and nonparents. This may, first, suggest that, although gratitude may be associated with positive emotional states and feelings of well-being, it is phenomenologically distinct from these states, and, secondly, that individuals with and without children experience similar levels of gratitude.

\subsection{Prospective Associations Between Gratitude and Symptoms of Psychopathology}

The findings from the current study shed more light on the previously suggested protective effects of gratitude against psychopathology (Petrocchi and Couyoumdjian 2016; Wood et al. 2008a). When not taking into account current symptoms of psychopathology, our study indeed found gratitude to be a highly significant, albeit weak negative predictor of future psychopathology symptoms, in line with previous research showing gratitude to longitudinally predict lower levels of stress, depression and anxiety (Kleiman et al. 2013; 
Krause 2009; Lies et al. 2014; Wood et al. 2008a). However, our study findings also revealed that the current presence of psychopathology is by far the strongest predictor of psychopathology in the future, irrespective of gratitude, and a lack of attention thereto may have led, in part, to exaggerated or imprecise findings regarding the protective effects of gratitude against psychopathology in previous reports.

Our findings are somewhat contradictory to those from a study by Wood et al. (2008a) in which higher levels of gratitude were longitudinally linked to lower levels of stress and depression, also when correcting for previous levels of these mental illness symptoms. However, the study by Wood et al. (2008a) specifically focused on the mechanics of gratitude during a life transition, and the study sample therefore consisted of first year undergraduate students (18-19 years old) who had just started their studies, whereas the current study was performed in a large, demographically diverse general population sample without a specific focus on life events. The discrepancy in findings between Wood et al.'s study (2008a) and ours may therefore suggest that the protective impact of gratitude on psychopathology is possibly more apparent in the context of a stressful life event, during which an individual undergoes changes in levels of mental health (Wheaton 1990), as further evidenced by longitudinal studies linking gratitude to post-traumatic growth (Tsai et al. 2016; Zhou and Wu 2015), and long-term survivorship in cancer patients (Hulett et al. 2015). Further longitudinal studies are needed, however, to systematically map the mechanics of gratitude in the context of adjustment and resilience to adversity.

\subsection{Prospective Associations Between Gratitude and Subjective Well-Being}

Our study findings showed that the grateful trait was a significant and positive, albeit weak predictor of subjective well-being in the future, also when accounting for the effect of demographic factors, and current levels of psychopathology and well-being. This finding adds further empirical support to previously reported longitudinal associations between gratitude and well-being (Gillham et al. 2011; Thrash et al. 2010), life satisfaction and positive emotions (Wood et al. 2008a).

The grateful trait may enhance subjective well-being through several previously described mechanisms (Wood et al. 2010). The first mechanism is the positive affect mechanism that considers gratitude a positive emotion, and predicts that feelings of positive affect and positive emotion act in a direct upward spiral toward enhanced subjective well-being (Fredrickson and Joiner 2002). Secondly, following the broaden-and-build mechanism of positive emotions (Fredrickson 2001), gratitude strengthens social bonds (Algoe et al. 2008; Bartlett et al. 2012; Kong et al. 2015) that in turn function as a resource for maintaining mental health in times of adversity (Fredrickson 2004; Kawachi and Berkman 2001). Thirdly, gratitude may lead to enhanced well-being through more adaptive coping, resulting in lower levels of stress, and enhanced subjective well-being (Wood et al. 2007). Fourth and lastly, grateful individuals view help as more costly, valuable, and altruistic, an appraisal scheme that may enhance subjective well-being (Wood et al. 2008c). Replicating the current study with additional attention to these mediating mechanisms will help to further our understanding of the pathways connecting the grateful trait to subjective well-being.

\subsection{Implications}

First, although the observed associations between gratitude and the demographic factors age, gender, education level, and employment status need replication in other large-scale 
systematic studies, our findings imply that a lack of attention to demographic confounders in gratitude research may yield imprecise results. This may be especially relevant when studying gratitude in relation to health-related outcomes, which are well-illustrated to also vary as a function of demography (Pol and Thomas 2013), and previous work has already hinted at complex interactions between gratitude and demographic factors in the context of mental health (Krause 2009). Further research into the mechanisms underlying associations between demographic factors and the grateful trait may increase our understanding of gratitude's contribution to mental health.

The findings from our prospective analyses based on self-report measures suggest that cultivating a sense of gratitude may impact positively on an individual's future position on the subjective well-being axis of mental health (Keyes 2005), regardless of its current levels of well-being and psychopathology, but an increased sense of gratitude is less likely to ameliorate symptoms of psychopathology when they are present. Gratitude interventions have been studied before and a recent meta-analysis by Davis et al. (2016) suggests that gratitude interventions such as gratitude journaling, the gratitude letter, and gratitude lists do increase subjective well-being, albeit with small effects. In line with the current study findings, recent research (Kerr et al. 2015) showed a gratitude intervention in a clinical sample to have no effect on general psychological functioning, but to have a positive impact on feelings of connectedness, satisfaction with daily life, and optimism. The authors of said study have suggested that gratitude interventions can contribute to positive emotional experience, and possibly stimulate change during psychotherapy or reduce negative affect in pre-treatment intervention when an individual is on the waiting list for psychotherapy (Kerr et al. 2015). Cultivating gratitude may thus indirectly decrease psychopathology, by increasing levels of subjective well-being modestly but significantly. Moreover, research has suggested that grateful individuals are less prone to develop symptoms of psychopathology from adversity because they are more able to positively reframe negative life events, possibly adding to the prevention of psychopathology (Emmons 2007; Watkins et al. 2004; Wood et al. 2008c).

Viewed in the light of practical significance, it needs to be acknowledged that the corrected prospective effect of gratitude on subjective well-being was rather small $(\beta=.09)$. However, first, we present findings from a non-experimental survey study, not aimed at manipulating certain variables under examination. Second, our results are based on multilevel regression modeling, with conservative statistical adjustment for demographic factors and fluctuations in subjective well-being and psychopathology over time. Indeed, the uncorrected prospective effect of gratitude on well-being was substantially larger $(\beta=.29$, see Table 1$)$, although still moderate at most. In comparison, the only study on gratitude and mental health with a comparable multi-wave study design and data analysis, although not applying correction for demographic factors, reported SEM path coefficients between gratitude and post-traumatic growth in the range of .12 to .15 (Zhou and Wu 2015), considered small by convention (Hu and Bentler 1999). Moreover, a recent meta-analysis (Davis et al. 2016) concluded the overall effect of gratitude interventions on well-being to range from moderate (Cohen's $d=.31$ ) to weak (Cohen's $d=.14$ ) in size, depending on control conditions, in line with a previous meta-analysis by Bolier et al. (2013), showing on average small effects of positive psychology interventions on wellbeing (Cohen's $d=.20$ ). However, despite the relatively small size of gratitude's effects on well-being reported in the literature, the grateful trait may have substantial relevance for an individual's subjective well-being, especially when considering the cumulative, upward spiral dynamic of positive emotion and personal and social resources (Fredrickson and Joiner 2002). Studies (see Wood et al. 2010 for review) suggest substantial incremental 
validity of the grateful trait for predicting well-being above other commonly studied traits, implying a unique and distinct impact of gratitude on well-being. At the population level, even interventions presenting small effect sizes can, in theory, have a large impact when many people are reached, and adherence is high (Huppert 2009). Using a self-help format to deliver gratitude interventions on a large scale, in combination with attention to factors affecting adherence, such as person-activity fit (Parks and Biswas-Diener 2013), tailoring (Schueller 2011), and interactive support (Cuijpers et al. 2010), may improve effectiveness of gratitude interventions for enhancing well-being.

\subsection{Strengths and Limitations}

The current study showed, for the first time, how the related but distinct dimensions of psychopathology and subjective well-being (Westerhof and Keyes 2010) vary as a function of gratitude when studied together prospectively. Further strengths of the study lie in the use of a four-wave prospective study design, spanning a total of 7.5 months, and collecting data from a large and demographically diverse sample. Multilevel regression techniques were used to test our prospective hypotheses, and we systematically corrected for the effects of demographic variation and correlations in psychopathology and subjective well-being across time in the prospective models under investigation. Despite these strengths, some limitations require consideration.

First, although the measures of subjective well-being and psychopathology used in the current study were selected for the specific purpose of optimizing comparability between our study and previous reports, they may paint an incomplete picture of complete mental health, defined by Keyes $(2002,2005)$ as the absence of mental illness, and the presence of positive mental health. Caution is warranted when extending the interpretation of our study findings to domains of mental health other than subjective well-being, and mental illness beyond current symptoms of psychopathology. Secondly, our findings could be affected by the normal but somewhat right skewed distribution in psychopathology symptoms and left skewed distribution in subjective well-being that was, however, inherent to the general population characteristics of the sample under examination. Thirdly, consideration should be given to a possible selectivity in study dropout with respect to respondent age, family status, and negative affect. There was a tendency for younger (vs. older) respondents, respondents living with (vs. without) underage children, and respondents with lower (vs. higher) negative affect at baseline, to more likely dropout of the study. However, apart from age (the baseline sample was significantly younger than the other samples), the sample did not differ in terms of demographic composition across the four measurements, and the aggregated measure of subjective well-being revealed no differences between dropouts and completers. Furthermore, all analyses were corrected for demographic factors, leaving it possible but unlikely that selectivity in dropout hampers the interpretation of our findings. Fourth and lastly, future research should incorporate measures of adverse life events to further elucidate whether the protective effect of gratitude on the development of psychopathology is more apparent in the context of a stressful life event.

\section{Conclusion}

To our knowledge, the present study is the first to systematically examine the demography of gratitude, and prospective associations between the grateful trait and both dimensions of complete mental health, in a large demographically diverse general population sample. 
First, our data do not support a uniform demographic distribution of gratitude, and suggest that a lack of attention to demographic confounders in gratitude research may yield imprecise results. In addition, we believe that further research into the mechanisms underlying associations between demographic factors and the grateful trait may provide important new leads in the empirical study of gratitude and its contributions to mental health.

Second, although our findings showed that the negative prospective effect of gratitude on psychopathology was reducible to correlations in psychopathology over time, the positive prospective effect of gratitude on subjective well-being, albeit weak, remained significant even when taking into account demographic factors, and variance in subjective well-being attributable to prior levels of both well-being and psychopathology. These results, thus, indicate that gratitude as a trait shows complex connections with the presence of well-being and absence of psychopathology, that should be taken into consideration when studying the dynamics of gratitude and mental health, and developing, applying, and evaluating gratitude interventions with the aim of enhancing subjective well-being and/or reducing psychopathology.

We encourage replication of our study in both general population and clinical study samples, and emphasize Keyes' (2007) recommendation of using a combined assessment of psychopathology and subjective well-being when studying mental health and its determinants.

\section{Compliance with Ethical Standards}

Conflict of interest All authors declare that they have no conflicts of interest.

Open Access This article is distributed under the terms of the Creative Commons Attribution 4.0 International License (http://creativecommons.org/licenses/by/4.0/), which permits unrestricted use, distribution, and reproduction in any medium, provided you give appropriate credit to the original author(s) and the source, provide a link to the Creative Commons license, and indicate if changes were made.

\section{References}

Adler, M. G., \& Fagley, N. S. (2005). Appreciation: Individual differences in finding value and meaning as a unique predictor of subjective well-being. Journal of Personality, 73(1), 79-114. doi:10.1111/j.14676494.2004.00305.x.

Algoe, S. B., Haidt, J., \& Gable, S. L. (2008). Beyond reciprocity: Gratitude and relationships in everyday life. Emotion, 8(3), 425-429. doi:10.1037/1528-3542.8.3.425.

Arrindell, W. (1991). The satisfaction with life scale (SWLS): Psychometric properties in a non-psychiatric medical outpatients sample. Personality and Individual Differences, 12(2), 117-123.

Arrindell, W., \& Ettema, J. (1981). Dimensionele structuur, betrouwbaarheid en validiteit van de Nederlandse bewerking van de Symptom Checklist (SCL-90): Gegevens gebaseerd op een fobisch en een" normale" populatie. Nederlands Tijdschrift voor de Psychologie en haar Grensgebieden, 36(2), 77-108.

Bartlett, M., Condon, P., Cruz, J., Baumann, J., \& Desteno, D. (2012). Gratitude: Prompting behaviours that build relationships. Cognitive Emotion, 26(1), 2-13. doi:10.1080/02699931.2011.561297.

Bolier, L., Haverman, M., Westerhof, G. J., Riper, H., Smit, F., \& Bohlmeijer, E. (2013). Positive psychology interventions: A meta-analysis of randomized controlled studies. BMC Public Health, 13(1), 119.

Carstensen, L. L., Fung, H. H., \& Charles, S. T. (2003). Socioemotional selectivity theory and the regulation of emotion in the second half of life. Motivation and Emotion, 27(2), 103-123.

Chaves, C., Hervas, G., García, F. E., \& Vazquez, C. (2015). Building life satisfaction through well-being dimensions: A longitudinal study in children with a life-threatening illness. Journal of Happiness Studies, 17(3), 1051-1067. doi:10.1007/s10902-015-9631-y. 
Clark, A. E., \& Oswald, A. J. (1994). Unhappiness and unemployment. The Economic Journal, 104(424), 648-659.

Cuijpers, P., Donker, T., van Straten, A., Li, J., \& Andersson, G. (2010). Is guided self-help as effective as face-to-face psychotherapy for depression and anxiety disorders? A systematic review and metaanalysis of comparative outcome studies. Psychological Medicine, 40(12), 1943-1957.

Davis, D. E., Choe, E., Meyers, J., Wade, N., Varjas, K., Gifford, A., et al. (2016). Thankful for the little things: A meta-analysis of gratitude interventions. Journal of Counseling Psychology, 63(1), 20-31. doi:10.1037/cou0000107.

Derogatis, L. R. (1977). SCL-90. Administration, scoring and procedures manual-II for the $R$ revised version and other instruments of the psychopathology rating scales series. Towson, MD: Clinical Psychometric Research.

Diener, E. (1994). Assessing subjective well-being: Progress and opportunities. Social Indicators Research, 31(2), 103-157.

Diener, E., Emmons, R. A., Larsen, R. J., \& Griffin, S. (1985). The satisfaction with life scale. Journal of Personality Assessment, 49(1), 71-75.

Eagly, A. H. (2013). Sex differences in social behavior: A social-role interpretation. Abingdon: Psychology Press.

Edmonds, G. W. (2011). Personality and the healthy lifestyle as predictors of physical health: Can the healthy lifestyle be explained by personality? (Doctoral dissertation, University of Illinois at UrbanaChampaign).

Emmons, R. A. (2007). Thanks!: How the new science of gratitude can make you happier. Boston: Houghton Mifflin Harcourt.

Emmons, R. A., \& Crumpler, C. A. (2000). Gratitude as a human strength: Appraising the evidence. Journal of Social and Clinical Psychology, 19(1), 56-69.

Feeney, B. C., \& Collins, N. L. (2014). Thriving through relationships. Current Opinion in Psychology, 1, $22-28$.

Fredrickson, B. L. (2001). The role of positive emotions in positive psychology: The broaden-and-build theory of positive emotions. American Psychologist, 56(3), 218-226. doi:10.1037/0003-066X.56.3. 218.

Fredrickson, B. L. (2004). Gratitude, like other positive emotions, broadens and builds. In R. A. Emmons \& M. E. McCullough (Eds.), The psychology of gratitude (pp. 230-255). New York: Oxford University Press.

Fredrickson, B. L., \& Joiner, T. (2002). Positive emotions trigger upward spirals toward emotional wellbeing. Psychological Science, 13(2), 172-175.

Gillham, J., Adams-Deutsch, Z., Werner, J., Reivich, K., Coulter-Heindl, V., Linkins, M., et al. (2011). Character strengths predict subjective well-being during adolescence. Journal of Positive Psychology, 6(1), 31-44. doi:10.1080/17439760.2010.536773.

Hansen, T. (2012). Parenthood and happiness: A review of folk theories versus empirical evidence. Social Indicators Research, 108(1), 29-64.

Hox, J. J. (1995). Applied multilevel analysis. Amsterdam: TT-publikaties Amsterdam.

Hu, L., Bentler, P. M. (1999). Cutoff criteria for fit indexes in covariance structure analysis: Conventional criteria versus new alternatives. Structural Equation Modeling: A Multidisciplinary Journal, 6(1), $1-55$.

Hulett, J. M., Armer, J. M., Stewart, B. R., \& Wanchai, A. (2015). Perspectives of the breast cancer survivorship continuum: Diagnosis through 30 months post-treatment. Journal of Personalized Medicine, 5(2), 174-190.

Huppert, F. A. (2009). A new approach to reducing disorder and improving well-being. Perspectives on Psychological Science, 4(1), 108-111.

Jans-Beken, L. G. P. J., Lataster, J., Leontjevas, R., \& Jacobs, N. (2015). Measuring gratitude: A comparative validation of the Dutch GQ6 and SGRAT. Psychologica Belgica. doi:10.5334/pb.bd.

Kaczmarek, L. D., Kashdan, T. B., Drążkowski, D., Enko, J., Kosakowski, M., Szäefer, A., et al. (2015). Why do people prefer gratitude journaling over gratitude letters? The influence of individual differences in motivation and personality on web-based interventions. Personality and Individual Differences, 75, 1-6.

Kashdan, T. B., Mishra, A., Breen, W. E., \& Froh, J. J. (2009). Gender differences in gratitude: Examining appraisals, narratives, the willingness to express emotions, and changes in psychological needs. Journal of Personality, 77(3), 691-730.

Kawachi, I., \& Berkman, L. F. (2001). Social ties and mental health. Journal of Urban Health, 78(3), 458-467. 
Kerr, S. L., O’Donovan, A., \& Pepping, C. A. (2015). Can gratitude and kindness interventions enhance well-being in a clinical sample? Journal of Happiness Studies, 16(1), 17-36.

Keyes, C. L. (2002). The mental health continuum: From languishing to flourishing in life. Journal of Health and Social Behavior, 43(2), 207-222.

Keyes, C. L. (2005). Mental illness and/or mental health? Investigating axioms of the complete state model of health. Journal of Consulting and Clinical Psychology, 73(3), 539-548. doi:10.1037/0022-006X.73. 3.539 .

Keyes, C. L. (2007). Promoting and protecting mental health as flourishing: A complementary strategy for improving national mental health. American Psychologist, 62(2), 95-108. doi:10.1037/0003-066X.62. 2.95 .

Kleiman, E. M., Adams, L. M., Kashdan, T. B., \& Riskind, J. H. (2013). Gratitude and grit indirectly reduce risk of suicidal ideations by enhancing meaning in life: Evidence for a mediated moderation model. Journal of Research in Personality, 47(5), 539-546. doi:10.1016/j.jrp.2013.04.007.

Kong, F., Ding, K., \& Zhao, J. (2015). The relationships among gratitude, self-esteem, social support and life satisfaction among undergraduate students. Journal of Happiness Studies, 16(2), 477-489.

Krause, N. (2006). Gratitude toward God, stress, and health in late life. Research on Aging, 28(2), 163-183.

Krause, N. (2009). Religious involvement, gratitude, and change in depressive symptoms over time. International Journal for the Psychology of Religion, 19(3), 155-172.

Kubacka, K. E., Finkenauer, C., Rusbult, C. E., \& Keijsers, L. (2011). Maintaining close relationships: Gratitude as a motivator and a detector of maintenance behavior. Personality and Social Psychology Bulletin, 37(10), 1362-1375. doi:10.1177/0146167211412196.

Kunzmann, U., Little, T. D., \& Smith, J. (2000). Is age-related stability of subjective well-being a paradox? Cross-sectional and longitudinal evidence from the Berlin Aging Study. Psychology and Aging, 15(3), 511-526.

Lies, J., Mellor, D., \& Hong, R. Y. (2014). Gratitude and personal functioning among earthquake survivors in Indonesia. The Journal of Positive Psychology, 9(4), 295-305. doi:10.1080/17439760.2014.902492.

McCullough, M. E., Emmons, R., \& Tsang, J. A. (2002). The grateful disposition: A conceptual and empirical topography. Journal of Personality and Social Psychology, 82(1), 112-127. doi:10.1037// 0022-3514.82.1.112.

Nelson, S. K., Kushlev, K., English, T., Dunn, E. W., \& Lyubomirsky, S. (2013). In defense of parenthood children are associated with more joy than misery. Psychological Science, 24(1), 3-10.

Parks, A. C., \& Biswas-Diener, R. (2013). Positive interventions: Past, present and future. In T. Kashdan \& J. Ciarrochi (Eds.), Mindfulness, Acceptance, and Positive Psychology: The Seven Foundations of Well-Being (pp. 140-165). Oakland: New Harbinger Publications.

Peeters, F. P. M. L., Ponds, R. H. W. M., \& Vermeeren, M. T. G. (1996). Affectiviteit en zelfbeoordeling van depressie en angst. Tijdschrift voor Psychiatrie, 38(3), 240-250.

Petrocchi, N., \& Couyoumdjian, A. (2016). The impact of gratitude on depression and anxiety: The mediating role of criticizing, attacking, and reassuring the self. Self and Identity, 15(2), 191-205. doi:10.1080/15298868.2015.1095794.

Pol, L. G., \& Thomas, R. K. (2013). The demography of health and health care (3rd ed.). Berlin: Springer.

R Core Team. (2016). R: A language and environment for statistical computing. Vienna: R Foundation for Statistical Computing.

Reed, A. E., Chan, L., \& Mikels, J. A. (2014). Meta-analysis of the age-related positivity effect: Age differences in preferences for positive over negative information. Psychology and Aging, 29(1), 1-15.

Revelle, W. (2014). psych: Procedures for psychological, psychometric, and personality research. Evanston: Northwestern University.

Schueller, S. M. (2011). To each his own well-being boosting intervention: Using preference to guide selection. The Journal of Positive Psychology, 6(4), 300-313.

Singh-Manoux, A., Ferrie, J. E., Chandola, T., \& Marmot, M. (2004). Socioeconomic trajectories across the life course and health outcomes in midlife: Evidence for the accumulation hypothesis? International Journal of Epidemiology, 33(5), 1072-1079. doi:10.1093/ije/dyh224.

Snyder, C. R., \& Lopez, S. J. (2009). Oxford handbook of positive psychology. Oxford: Oxford University Press.

Sommers, S., \& Kosmitzki, C. (1988). Emotion and social context: An American-German comparison. British Journal of Social Psychology, 27(1), 35-49.

StataCorp. (2015). Stata statistical software: Release 14. College Station, TX: StataCorp LP.

Šverko, B., \& Vidović, V. V. (1995). Studies of the meaning of work: Approaches, models and some of the findings. In D. E. Super, B. Sverko \& C. M. Super (Eds.), Life roles, values and careers. Jossey-Bass.

Szcześniak, M., \& Soares, E. (2011). Are proneness to forgive, optimism and gratitude associated with life satisfaction? Polish Psychological Bulletin, 42(1), 20-23. 
Terwee, C. B., Bot, S. D., de Boer, M. R., van der Windt, D. A., Knol, D. L., Dekker, J., et al. (2007). Quality criteria were proposed for measurement properties of health status questionnaires. Journal of Clinical Epidemiology, 60(1), 34-42.

Thomas, M., \& Watkins, P. (2003). Measuring the grateful trait: Development of revised GRAT. In Paper presented at the annual convention of the Western Psychological Association, Vancouver

Thrash, T. M., Elliot, A. J., Maruskin, L. A., \& Cassidy, S. E. (2010). Inspiration and the promotion of wellbeing: Tests of causality and mediation. Journal of Personality and Social Psychology, 98(3), 488-506. doi:10.1037/a0017906.

Tsai, J., Sippel, L. M., Mota, N., Southwick, S. M., \& Pietrzak, R. H. (2016). Longitudinal course of posttraumatic growth among U.S. military veterans: Results from the national health and resilience in veterans study. Depression and Anxiety, 33, 9-18. doi:10.1002/da.22371.

Van Beuningen, J. (2012). The satisfaction with life scale examining construct validity. Den Haag: Statistics Netherlands.

Watkins, P. (2013). Gratitude and the good life: Toward a psychology of appreciation. Dotretch: Springer.

Watkins, P., Grimm, D. L., \& Kolts, R. (2004). Counting your blessings: Positive memories among grateful persons. Current Psychology, 23(1), 52-67.

Watkins, P., Woodward, K., Stone, T., \& Kolts, R. (2003). Gratitude and happiness: Development of a measure of gratitude and relationships with subjective well-being. Social Behavior and Personality, 31(5), 431-451.

Watson, D., Clark, L. A., \& Tellegen, A. (1988). Development and validation of brief measures of positive and negative affect: The PANAS scales. Journal of Personality and Social Psychology, 54(6), 1063-1070. doi:10.1037/0022-3514.54.6.1063.

Westerhof, G. J., \& Keyes, C. L. M. (2010). Mental illness and mental health: The two continua model across the lifespan. Journal of Adult Development, 17(2), 110-119. doi:10.1007/s10804-009-9082-y.

Wheaton, B. (1990). Life transitions, role histories, and mental health. American Sociological Review, 55(2), 209-223.

Wilson, S. H., \& Walker, G. M. (1993). Unemployment and health: A review. Public Health, 107(3), 153-162.

Wood, A. M., Froh, J. J., \& Geraghty, A. W. A. (2010). Gratitude and well-being: A review and theoretical integration. Clinical Psychology Review, 30(7), 890-905. doi:10.1016/j.cpr.2010.03.005.

Wood, A. M., Joseph, S., \& Linley, P. A. (2007). Coping style as a psychological resource of grateful people. Journal of Social and Clinical Psychology, 26(9), 1076-1093.

Wood, A. M., Maltby, J., Gillett, R., Linley, P. A., \& Joseph, S. (2008a). The role of gratitude in the development of social support, stress, and depression: Two longitudinal studies. Journal of Research in Personality, 42(4), 854-871. doi:10.1016/j.jrp.2007.11.003.

Wood, A. M., Maltby, J., Stewart, N., \& Joseph, S. (2008b). Conceptualizing gratitude and appreciation as a unitary personality trait. Personality and Individual Differences, 44(3), 621-632. doi:10.1016/j.paid. 2007.09.028

Wood, A. M., Maltby, J., Stewart, N., Linley, P. A., \& Joseph, S. (2008c). A social-cognitive model of trait and state levels of gratitude. Emotion, 8(2), 281-290. doi:10.1037/1528-3542.8.2.281.

Zhou, X., \& Wu, X. (2015). Longitudinal relationships between gratitude, deliberate rumination, and posttraumatic growth in adolescents following the wenchuan earthquake in china. Scandinavian Journal of Psychology, 56(5), 567-572. doi:10.1111/sjop.12237. 